\title{
Capsule Commentary on Moreno et al., Disparities in the Use of Internet and Telephone Medication Refills Among Linguistically Diverse Patients
}

\author{
Courtney R. Lyles, PhD $1,2,3$ \\ 'Division of General Internal Medicine at San Francisco General Hospital, University of California San Francisco, San Francisco, CA, USA; ${ }^{2}$ Center for

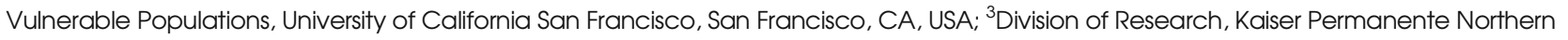 \\ California, Oakland, CA, USA.
}

$\mathrm{J}$ Gen Intern Med 31(3):322

DOI: $10.1007 / \mathrm{s} 11606-015-3520-2$

(c) Society of General Internal Medicine 2015

$\mathrm{M}$ oreno et al. ${ }^{1}$ examine the relationship between English proficiency and use of remote medication refill systems (that is, requesting to refill medications through automated phone or online systems rather than in person). They find that only $46 \%$ of limited English proficient (LEP) patients with chronic illness use these services, compared to $83 \%$ of English proficient patients. This discrepancy is not surprising, given that the majority of healthcare systems in the US offer these refill services only in English. The differences between English proficient and LEP patients were more pronounced for online refilling than telephone refilling, which may indicate unique barriers to online portal use among this patient subgroup. Overall, this work is consistent with growing evidence that patients with communication barriers are less likely to be able to access a variety of healthcare tools (particularly online tools) that are often designed and implemented for the mainstream patient population. ${ }^{2}$

The study also supports the longstanding hypothesis of the "inverse care law," ${ }^{3}$ which states that the most well resourced individuals are the first to gain from the introduction of a new technology or service. The inverse care law is most problematic in exacerbating existing health/health care disparities when the technology confers a direct health benefit. We should be concerned about this issue because there is evidence that patients who use both telephone and online refilling systems have significantly improved medication adherence (a health behavior that is clinically important, but often difficult to influence). ${ }^{4,5}$

There is much more work to be done in this area. In particular, we need more research on why these barriers exist and how to overcome them. Technology offers a seemingly streamlined and efficient way to provide services tailored to the needs and preferences of the target group. Moreover, online patient portals are becoming a new standard for patient communication in health care; we will continue to offer more and more healthcare services through these websites to improve efficiency of care. Therefore, it is critical to focus on accessibility and usability upfront and guarantee that these services are available in languages other than English. If our bank ATMs can ask and remember our preferred language, isn't it time for our health care system to design communication technologies that do the same?

Conflict of Interest: The author has no conflicts of interest with this article.

Corresponding Author: Courtney R. Lyles, PhD; Division of General Internal Medicine at San Francisco General Hospital, University of California San Francisco, San Francisco, CA, USA (e-mail: courtney.lyles@ucsf.edu).

\section{REFERENCES}

1. Moreno G, Lin EH, Chang E, Johnson RL, Johnson RL, Berthoud H, Solomon CC, Morales LS. Disparities in the use of Internet and telephone medication refills among linguistically diverse patients. J Gen Intern Med. DOI: $10.1007 / \mathrm{s} 11606-015-3500-6$

2. Lyles C, Schillinger D, Sarkar U. Connecting the dots: health information technology expansion and health disparities. PLoS Med. 2015;12(7), el001852.

3. Schillinger D. Literacy and health communication: reversing the 'inverse care law'. Am J Bioeth. 2007;7(11):15-18. discussion W11-12.

4. Sarkar U, Lyles CR, Parker MM, et al. Use of the refill function through an online patient portal is associated with improved adherence to statins in an integrated health system. Med Care. 2014;52(3):194-201.

5. Duru OK, Schmittdiel JA, Dyer WT, et al. Mail-order pharmacy use and adherence to diabetes-related medications. Am J Manage Care. 2010;16(1):33-40.

This comment refers to the article available at: $h t t p: / / d x . d o i . o r g / 10.1007 /$ s11606-015-3500-6.

Published online September 21, 2015 